\title{
COMPOSIÇÃO LIGNOCELULÓSICA E ISÓTOPICA DA VEGETAÇÃO E DA MATÉRIA ORGÂNICA DO SOLO DE UMA TURFEIRA TROPICAL. II - SUBSTÂNCIAS HÚMICAS E PROCESSOS DE HUMIFICAÇÃOO ${ }^{(1)}$
}

\author{
Alexandre Christofaro Silva ${ }^{(2)}$, Vinicius Evangelista Silva ${ }^{(3)}$, Bárbara Pereira Christofaro \\ Silva $^{(4)}$, Plínio Barbosa de Camargo ${ }^{(5)}$, Rosana Cristina Pereira ${ }^{(6)}$, Uidemar Morais \\ Barral $^{(4)}$, Ana Maria Martins Botelho ${ }^{(4)} \&$ Pablo Vidal Torrado ${ }^{(7)}$
}

\begin{abstract}
RESUMO
Grande parte da matéria orgânica de Organossolos das turfeiras é composta por substâncias húmicas, formadas pela transformação de resíduos orgânicos pelos microrganismos do solo e pela polimerização dos compostos orgânicos em macromoléculas resistentes à degradação biológica. Os processos de humificação da matéria orgânica do solo (MOS) ainda são pouco compreendidos e o conhecimento sobre os precursores das substâncias húmicas é limitado, sendo apresentadas rotas diferentes para a formação dessas substâncias. Contudo, em todas as rotas, destaca-se a participação da lignina. Isótopos estáveis $\left({ }^{13} \mathrm{C},{ }^{15} \mathrm{~N}\right)$ podem ser utilizados para rastrear processos de humificação da MOS, por meio da identificação de seus precursores. Este trabalho teve como objetivo avaliar comparativamente a composição isotópica da vegetação das fitofisionomias que colonizam uma turfeira tropical de altitude composta de Campo Limpo Úmido (CLU) e de Floresta Estacional Semidecidual (FES), em relação à composição
\end{abstract}

(1) Parte de Dissertação de Mestrado do segundo autor apresentada ao Programa de Pós-Graduação em Produção Vegetal da Universidade Federal dos Vales do Jequitinhonha e Mucuri - UFVJM. Recebido para publicação em 19 de março de 2012 e aprovado em 30 de outubro de 2012.

(2) Professor Associado do Departamento de Engenharia Florestal da UFVJM. Rodovia MGT 367, km 583. CEP 39100-000 Diamantina (MG). E-mail: alexandre.christo@ufvjm.edu.br

${ }^{(3)}$ Engenheiro Florestal da Empresa Eldorado Brasil Celulose S/A. Av. Aldair Rosa de Oliveira, 1036. CEP 79640-100 Três Lagoas (MS). E-mail: vinicius.silva@eldoradobrasil.com.br

(4) Bolsista de Iniciação Científica da UFVJM. E-mail: barbarachrsitofaro@hotmail.com

(5) Professor Associado do Centro Nacional de Energia Nuclear na Agricultura - CENA/USP. Av. Centenário, 303. CEP 13416-000 Piracicaba (SP). E-mail: pcamargo@cena.usp.br

(6) Pós-doutoranda do Programa de Pós-Graduação em Produção Vegetal da UFVJM. E-mail: rosanac_pereira@yahoo.com.br

(7) Professor titular do Departamento de Ciência do Solo, Escola Superior de Agricultura "Luiz de Queiroz" - ESALQ/USP. Av. Pádua Dias, 11. Caixa Postal 09. CEP 13418-900 Piracicaba (SP). E-mail: pvidal@usp.br 
isotópica das substâncias húmicas da MOS. A turfeira estudada ocupa 81,75 ha. Para as análises isotópicas e lignocelulósicas da vegetação, foram identificadas as espécies dominantes em cada fitofisionomia. Amostras de solo foram coletadas em três locais representativos sob cada fitofisionomia, a cada $5 \mathrm{~cm}$ de profundidade, até $50 \mathrm{~cm}$. As substâncias húmicas dessas amostras foram fracionadas, assim como calculados os valores de $\delta^{13} \mathrm{C}$ e $\delta^{15} \mathrm{~N}$ nas frações húmicas, respectivamente a partir da determinação dos isótopos estáveis ${ }^{12} \mathrm{C} \mathrm{e}{ }^{13} \mathrm{C} e^{14} \mathrm{~N}$ e ${ }^{15} \mathrm{~N}$. Os teores de lignina e seus valores de $\delta^{13} \mathrm{C}$ são mais elevados na vegetação e MOS sob FES em relação à vegetação e MOS sob CLU. Os teores de humina são mais elevados entre as substâncias húmicas na MOS, sob as duas fitofisionomias; os de ácidos húmicos são mais elevados na MOS sob CLU, em relação à FES; e os de ácidos fúlvicos são mais elevados na MOS sob a FES, em relação ao CLU. $O \delta^{13} \mathrm{C}$ da lignina apresenta similaridade elevada em relação ao $\delta^{13} \mathrm{C}$ da humina, dos ácidos húmicos e dos ácidos fúlvicos. As variações na composição lignocelulósica das espécies que colonizam o CLU e a FES promovem diferenças nas taxas e nos produtos da humificação da MOS.

Termos de indexação: Organossolo, $\delta^{13} \mathrm{C}$ e $\delta{ }^{15} \mathrm{~N}$, ácidos fúlvicos, ácidos humicos, humina, fitofisionomias.

\title{
SUMMARY: LIGNOCELLULOSIC AND ISOTOPIC COMPOSITION OF VEGETATION AND SOIL ORGANIC MATTER OF A TROPICAL PEAT. II HUMIC SUBSTANCES AND HUMIFICATION PROCESSES
}

\begin{abstract}
Much of the organic matter of a typical peat consists of humic substances, mainly formed via humification of organic residues, decomposed by soil microorganisms, and by the polymerization of organic compounds to functional macromolecules, which are normally more resistant to degradation. The fundamental pathways governing the humification of soil organic matter (SOM) are not well understood so far, and most available data about the identified chemical precursors of humic substances and the main chemical routes by which they are transformed in the peat environment are still poorly understood. What is clear is that all routes involve lignin as a chemical intermediate. Stable isotopes $\left(\delta^{13} C, \delta^{15} N\right)$ can be used to trace humification processes of the soil organic matter (SOM), by identifying their precursors. The purpose of this study was to compare the isotopic composition of vegetation materials from the two bog vegetation types that colonize a tropical highland peatland: moist grassland (CLU) and semideciduous forest (FES), based on the isotopic composition of humic substances of SOM. The whole area of the studied peatland occupies 81.75 ha. To identify the isotopic and lignocellulosic vegetation composition, materials of the dominant species of each vegetation type were sampled. Soil samples were collected from three representative sites per vegetation type, at intervals of $5 \mathrm{~cm}$ from the surface down to a depth of $50 \mathrm{~cm}$. The humic substances were isolated from these samples; signals of $\delta^{13} \mathrm{C}$ and $\delta^{15} \mathrm{~N}$ were determined for the humic fractions. The lignin and and $\delta^{13} C$ values were higher in vegetation and SOM under FES than in SOM under CLU. Humin contents were high in SOM under both vegetation types; the levels of humic acids were higher in SOM under CLU than in FES; fulvic acid contents were higher in SOM under FES than CLU. The ${ }^{13} \mathrm{C}$ values for lignin were highly similar to those for humic acids and fulvic acids. Variations in the lignocellulosic composition of the species that colonize the CLU and FES promote different rates and SOM humification products.
\end{abstract}

Index terms: Histosols, $\delta^{13} \mathrm{C}$ and $\delta^{15} \mathrm{~N}$, fulvic acids, humic acids, humin, vegetation types.

\section{INTRODUÇÃO}

As turfeiras são ecossistemas formados por Organossolos, cuja gênese resulta de condições pedoclimáticas ideais ao acúmulo de material orgânico, controladas pelos sistemas geomorfológicos e processos geológicos e climáticos globais (Silva, 2009a). Grande parte de sua matéria orgânica é composta por substâncias húmicas (ácidos fúlvicos, ácidos húmicos e humina), formadas pela transformação de resíduos orgânicos pelos microrganismos do solo e pela polimerização dos compostos orgânicos em macromoléculas resistentes à degradação biológica (Canellas \& Santos, 2005). 
Os processos de humificação da matéria orgânica do solo (MOS) ainda são pouco compreendidos e o conhecimento sobre os precursores das frações húmicas ainda é limitado. De acordo com Stevenson (1982) e Canellas \& Santos (2005), o conhecimento sobre a formação das frações húmicas ainda é incompleto e diversos autores apresentam rotas diferentes para sua formação. Contudo, em todas essas rotas, o destaque especial é dado à participação da lignina (Waksman \& Hutchings, 1936; Stevenson, 1994; Sparks, 1995; Breemen \& Buurman, 1998; Tan, 2003; Dick et al., 2005).

Estudos relacionados com a dinâmica da matéria orgânica em turfeiras tropicais, principalmente no que tange à sua humificação, ainda são incipientes, notadamente no Brasil. A maioria das pesquisas relacionadas aos processos da humificação está concentrada nas regiões de clima temperado (Bayer et al., 2003).

Isótopos são espécies atômicas de um mesmo elemento químico com mesmo número de prótons, mas com massas diferentes. O termo "Isótopos Estáveis" ou não radioativos é definido pela constância das massas ao longo de sua existência (Martinelli et al., 2009). A aplicabilidade dos isótopos estáveis em estudos ambientais baseia-se no principio que a composição isotópica varia de forma previsível, conforme o elemento se movimenta nos compartimentos dos ecossistemas (Farquhar et al., 1982). Dessa forma, pode-se inferir sobre processos físicos, químicos e biológicos, por meio do enriquecimento ou empobrecimento do isótopo leve (abundante), em relação ao pesado (raro), tendo como referência um padrão internacional.

As plantas, tendo como base a diferenciação entre os ciclos fotossintéticos, discriminam carbono (C) da seguinte maneira: espécies $\mathrm{C}_{3}$ : -38 a $-24 \%$ de $\delta^{13} \mathrm{C}$; espécies $\mathrm{C}_{4}$ : -17 a $-9 \%$ de $\delta^{13} \mathrm{C}$; e espécies CAM: -28 a $-10 \%$ de $\delta^{13} \mathrm{C}$ (O'Leary, 1988; Boutton, 1991; Freitas et al., 2001; Sanaiotti et al., 2002). O $\delta^{13} \mathrm{C}$ é calculado a partir de relação entre o isótopo abundante e o isótopo raro na amostra e em um padrão internacional. Uma série de análises isotópicas evidenciou que os valores de $\delta^{13} \mathrm{C}$ da MOS seguem os valores isotópicos da vegetação presente (Victoria et al., 1995; Gouveia et al., 2002; Martinelli et al., 2009). No entanto, além do fracionamento entre o $\mathrm{CO}_{2}$ atmosférico e a fotossíntese, outros processos são identificados por meio dos valores de $\delta^{13} \mathrm{C}$, como a decomposição de material vegetal fresco no solo pela ação dos microrganismos decompositores (Martinelli et al., 1996). Entre a vegetação e a serapilheira e entre esta e o solo, ocorre, respectivamente, um enriquecimento aproximado de 1 a $2 \%$ e de $2 \%$, nos valores de $\delta^{13} \mathrm{C}$ (Martinelli et al., 2009).

As fontes de nitrogênio $(\mathrm{N})$ para as plantas são inúmeras e, por esse motivo e pela complexidade do seu ciclo, os isótopos de $\mathrm{N}$ são pouco utilizados em estudos ambientais (Boutton, 1996). No entanto, mesmo diante da complexidade de fontes e das várias rotas envolvidas no ciclo do $\mathrm{N}$, existem vários estudos que remetem a processos importantes envolvendo $\delta^{15} \mathrm{~N}$ da MOS para identificar diferenças na disponibilidade de N (Högberg, 1997).

Considerando que estudos anteriores demonstraram que os valores de $\delta^{13} \mathrm{C}$ da MOS se assemelham aos valores isotópicos da vegetação presente (Victoria et al., 1995), a comparação dos teores de $\delta^{13} \mathrm{C}$ da lignina e da celulose de espécies vegetais que colonizam uma área, com os teores de $\delta^{13} \mathrm{C}$ das substâncias húmicas da MOS, poderia contribuir para acelerar o entendimento do processo de humificação da MOS em turfeiras tropicais. No entanto, o estudo da dinâmica da matéria orgânica em regiões tropicais utilizando essa abordagem pouco convencional é incomum.

A turfeira estudada é colonizada por vegetação de campo higrófilo com ocorrência de fragmentos localizados de floresta, que apresentam espécies de ciclo fotossintético $\mathrm{C}_{3}$ e $\mathrm{C}_{4}$ e diferenças na composição lignocelulósica (Silva et al., 2012). Hipoteticamente, essas diferenças podem ser rastreadas na MOS, utilizando-se o $\delta^{13} \mathrm{C}$ das substâncias húmicas, no intuito de identificar seus precursores.

Este trabalho teve como objetivo avaliar comparativamente a composição isotópica da vegetação das fitofisionomias que colonizam uma turfeira de clima tropical úmido de altitude, em relação à composição isotópica das substâncias húmicas da MOS, com intuito de contribuir para o entendimento de processos de humificação.

\section{MATERIAL E MÉTODOS}

\section{Caracterização da Área}

A turfeira estudada se estende por 81,75 ha (Campos, 2009) e está inserida na APA Pau-de-Fruta. Localiza-se a $6 \mathrm{~km}$ de Diamantina, entre as coordenadas geográficas $18^{\circ} 16^{\prime} 22^{\prime \prime}$ e $18^{\circ} 15^{\prime} 17^{\prime \prime}$ de latitude sul e $43^{\circ} 41^{\prime} 10^{\prime \prime}$ e $43^{\circ} 39^{\prime} 15^{\prime}$, de longitude oeste. A altitude média é de $1.250 \mathrm{~m}$.

Duas fitofisionomias do bioma Cerrado colonizam a turfeira: o Campo Limpo Úmido (CLU) e a Floresta Estacional Semidecidual (FES) (Silva et al., 2005). O CLU é formado predominantemente por espécies herbáceas, adaptadas a condições de drenagem deficiente (Munhoz \& Felfili, 2008). As ilhas de FES ou popularmente "Capões de Mata" são formadas por espécies de hábito arbóreo-arbustivo e ocorrem de forma esparsa na turfeira (Horák et al., 2011).

Detalhes da localização, das espécies que compõe cada fitofisionomia e da sua composição lignocelulósica encontram-se em Silva et al. (2012).

\section{Amostragem da turfeira}

Foram escolhidos três locais representativos em cada fitofisionomia da turfeira da APA Pau-de-Fruta, 
onde, com auxílio de uma pá reta, coletaram-se amostras de solo a cada $5 \mathrm{~cm}$ de profundidade, até 50 $\mathrm{cm}$, totalizando 10 amostras em cada ponto e 60 amostras no total.

\section{Determinação das substâncias húmicas}

As 60 amostras das camadas do Organossolo foram colocadas para secar ao ar e, em seguida, destorroadas e passadas em peneiras de malha de $2 \mathrm{~mm}$. As amostras peneiradas foram colocadas para secar em estufa com circulação de ar a $50^{\circ} \mathrm{C}$, durante $12 \mathrm{~h}$. O fracionamento químico da MOS foi feito segundo método adaptado da International Humic Substances Society (IHSS) e Canellas \& Santos (2005). Resumidamente, $20 \mathrm{~g}$ de solo seco em estufa a 105/ $110{ }^{\circ} \mathrm{C}$ por $24 \mathrm{~h}$ foram agitadas durante $12 \mathrm{~h}$ em atmosfera inerte $\left(\mathrm{N}_{2}\right)$ em $200 \mathrm{~mL}$ de solução $\mathrm{NaOH}$ $0,1 \mathrm{~mol} \mathrm{~L}^{-1}$. Os extratos foram centrifugados a 14,250 g por $30 \mathrm{~min}$, separados dos resíduos e, posteriormente, os sobrenadantes foram centrifugados novamente, coletados e acidificados a pH 1-2 com $\mathrm{HCl} 6 \mathrm{~mol} \mathrm{~L}^{-1} \mathrm{e}$ decantados por $12 \mathrm{~h}$. Os ácidos húmicos $(\mathrm{AH})$ precipitaram e foram separados dos ácidos fúlvicos (AF) por sifonamento; os últimos foram centrifugados a $14,250 \mathrm{~g}$, durante $30 \mathrm{~min}$. Os AF extraídos foram liofilizados e, posteriormente, secos em estufa a $40^{\circ} \mathrm{C}$ e pesados. Nos AF liofilizados, o conteúdo de cinzas foi determinado, queimando-se $20 \mathrm{mg}$ de $\mathrm{AF}$ a $600^{\circ} \mathrm{C}$, durante $4 \mathrm{~h}$. Após a separação dos AF, os AH foram dissolvidos em solução KOH $0,1 \mathrm{~mol} \mathrm{~L}^{-1}+\mathrm{KCl}$ para atingir a concentração de $0,3 \mathrm{~mol} \mathrm{~L}^{-1} \mathrm{de} \mathrm{K}^{+} \mathrm{e}$ centrifugados novamente. Os AH foram ressuspensos em uma solução de $\mathrm{HCl} 0,1 \mathrm{~mol} \mathrm{~L}^{-1}+\mathrm{HF} 0,3 \mathrm{~mol} \mathrm{~L}^{-1}$, agitados durante $12 \mathrm{~h}$, centrifugados, dialisados com água ultrapura em membrana de 6.000-8.000 Dalton até a condutividade elétrica da solução ser menor que $10 \mu \mathrm{S} \mathrm{cm}^{-1} \mathrm{e}$ liofilizada; posteriormente, foram secos em estufa a $40^{\circ} \mathrm{C}$ e pesados. Nos AH liofilizados, o conteúdo de cinzas foi determinado, queimando-se $20 \mathrm{mg}$ de $\mathrm{AH}$ a $600{ }^{\circ} \mathrm{C}$, durante $4 \mathrm{~h}$. O material que permaneceu precipitado após a separação dos AH corresponde à humina $(\mathrm{H})$, que foi seca em estufa a $40^{\circ} \mathrm{C}$ e pesada. $\mathrm{O}$ conteúdo de cinzas desse material foi determinado, queimando-se $20 \mathrm{mg}$ de humina a $600^{\circ} \mathrm{C}$, durante $4 \mathrm{~h}$.

\section{Determinações isotópicas de $\mathbf{C}$ e de $\mathbf{N}$}

Para a determinação da composição isotópica, as amostras das substâncias húmicas foram secas em estufa a $40^{\circ} \mathrm{C}$, homogeneizadas em almofariz de ágata e pesadas em cápsulas de estanho. Aproximadamente $3,5 \mathrm{mg}$ de cada amostra foram usadas para determinar os valores de $\delta^{13} \mathrm{C}, \delta^{15} \mathrm{~N}, \%$ de $\mathrm{C}$ e de $\mathrm{N}$, em um espectrômetro de massas, de acordo com método preconizado por Groning \& Groot (2004).

Os métodos utilizados para determinar a composição isotópica da vegetação, dos compostos lignocelulósicos, bem como da MOS, estão detalhadamente descritos em Silva et al. (2012).

\section{Análises estatísticas}

Para avaliar diferenças no teor das substâncias húmicas entre as fitofisionomias e as camadas de turfeira, usou-se o delineamento em blocos casualizados em esquema fatorial triplo, sendo os tratamentos as três frações húmicas, as duas fitofisionomias e as 10 profundidades, com três repetições, totalizando 60 parcelas (Pimentel-Gomes, 1987).

Com o intuito de identificar os precursores das frações húmicas do solo, foi usada a análise estatística multivariada (Hair et al., 2005), utilizando-se a análise de agrupamento para agrupar os valores isotópicos das substâncias húmicas em razão dos valores de $\delta^{13} \mathrm{C}$ da celulose e da lignina do solo.

\section{RESULTADOS E DISCUSSÃO}

\section{Substâncias húmicas na MOS}

\section{Humina}

O teor médio de humina não variou entre as fitofisionomias (Anova, $p=0,373397$ ), mas é mais alto na MOS sob o CLU $(61,8 \%)$ em relação à $\operatorname{FES~}(56,5 \%)$. O húmus se forma no solo por meio de duas rotas, descritas simplificadamente: a preservação seletiva de biopolímeros e a policondensação de moléculas pequenas (Camargo et al., 1999). Analisando em conjunto os teores de humina e os de lignina+celulose (Silva et al., 2012), infere-se que a preservação de biopolímeros é mais intensa no solo sob a FES do que sob o CLU, pois os teores de lignina+celulose na FES $(53,6 \%)$ estão mais próximos do teor médio de humina do que no CLU (43,2\%). Portanto, sugere-se que no CLU os processos de policondensação de micromoléculas e de algumas ceras, como a cutina e o N-lignificado, ocorram com maior intensidade.

Geralmente, o processo de humificação segue a seguinte ordem na formação de seus produtos: humina => ácido húmico => ácido fúlvico (Stevenson, 1994; Canellas \& Santos, 2005). A evolução da humificação é retardada pelo acentuado hidromorfismo (Silva et al., 2009b; Campos et al., 2010). Em solos muito mal drenados, a via de herança ou a preservação de biopolímeros é o processo de humificação predominante, pois as outras vias de humificação, como a de neossíntese microbiana ou a policondensação de micromoléculas e a de insolubilização ou humificação dos compostos fenólicos solúveis, necessitam de elevada pressão de $\mathrm{O}_{2}$ para manter a atividade da microbiota do solo (Dabin, 1981).

Além disso, o elevado teor de humina foi associado ao baixo teor de bases trocáveis nos solos orgânicos (Campos et al., 2010), em especial de cálcio (Canellas \& Santos, 2005). Para Fernandes et al. (1999), o aumento do teor de cálcio acelera a humificação, pois tem papel importante na formação de humatos de cálcio (Oades, 1988). Diante desse contexto, nota-se, de forma 
geral, que a MOS da turfeira encontra-se em fase inicial de humificação por causa da predominância da fração humina, pois o ambiente apresenta baixa disponibilidade de $\mathrm{O}_{2}$, que inibe a atividade de microrganismos decompositores. Campos et al. (2010) observaram que a atividade microbiológica nessa mesma turfeira é cerca de 10 vezes menor do que a atividade microbiológica média em solos minerais bem drenados.

O teor de humina não variou em profundidade. Em uma escala de solubilidade ácido-base, a humina é a fração menos solúvel (Stevenson, 1994; Canellas \& Santos, 2005), além do seu comportamento recalcitrante em razão da elevada relação $\mathrm{C} / \mathrm{N}$. Dessa forma, geralmente a acumulação de humina ocorre quando o teor de MOS é mais elevado (Horák et al., 2007; Silva et al., 2009b). Entretanto, na figura 1, observa-se tendência de aumento no teor de humina em profundidade sob a FES, provavelmente por causa da natureza recalcitrante da lignina no solo, principalmente das raízes das árvores (Hartshorn, 1980).

\section{Ácidos Húmicos}

O teor médio de AH é maior na MOS sob o CLU $(22,0 \%)$ em relação à FES $(15,5 \%)$ (Anova, $\mathrm{p}=0,046632$ ), mas não variou com a profundidade. No entanto, observou-se tendência de homogeneidade em profundidade na FES em relação ao CLU (Figura 1). As idades radiocarbônicas evidenciaram que a MOS sob FES é moderna e a idade da MOS sob CLU varia de moderna na superfície a 3.480 anos AP na camada de 45 a $50 \mathrm{~cm}$ (Silva et al., 2012). Dessa forma, a idade bem mais antiga da MOS no CLU poderia ser fator preponderante no maior teor de $\mathrm{AH}$.

\section{Ácidos Fúlvicos}

O teor médio de AF é maior na MOS sob a FES $(26,2 \%)$, em relação ao CLU (16,1 \%) (Anova, $\mathrm{p}=0,004758)$. Em solos florestais, é amplamente conhecida a predominância de $\mathrm{AF}$, em relação aos $\mathrm{AH}$ (Duchaufour, 1977; Garay et al., 1995; Loss et al., 2006; Fontana et al., 2008; Pulrolnik et al., 2009). De forma geral, os AF são formados em solos distróficos (Canellas \& Santos, 2005), independentemente das condições de drenagem (Cerri \& Volkoff, 1988) e, além disso, especificamente nos Organossolos com menor teor de C (Valladares, 2003; Silva et al., 2009a).

Os teores de AF não variaram em subsuperfície, até a profundidade de $50 \mathrm{~cm}$ (Figura 1). Campos et al. (2010), entretanto, observaram maiores teores de AF nas camadas mais profundas $(189-216 \mathrm{~cm})$ da mesma turfeira deste estudo e atribuíram esse comportamento à sua elevada mobilidade vertical.

\section{Evolução do processo de humificação}

A relação $\mathrm{AH} / \mathrm{AF}$ foi maior no solo sob $\mathrm{CLU}(2,0)$ em relação ao sob FES $(1,0)$ (Anova, $\mathrm{p}=0,037625$ ) e está dentro da faixa encontrada pela Embrapa (2003) para Organossolos brasileiros, que variou de 1,47 a 14,41. Valores da relação $\mathrm{AH} / \mathrm{AF}$ inferiores a 1 podem indicar avanço lento da humificação da MOS em razão das razões edáficas ou de manejo, além de aportes recentes de matéria orgânica (Canellas \& Santos, 2005).

Em profundidade, a relação $\mathrm{AH} / \mathrm{AF}$ foi homogênea sob as duas fitofisionomias. Entretanto, nota-se que no solo sob CLU houve incremento dessa relação entre 35 e $45 \mathrm{~cm}$ (Figura 2). As fontes de compostos alifáticos incluem componentes macromoleculares provenientes de plantas, as chamadas cutinas e suberinas (Nierop, 1998), abundantes no CLU (Silva, 2011) e altamente resistentes à degradação biológica (Lichtfouse et al., 1995). A decomposição lenta desses componentes ocasiona a formação das frações alcalino-solúveis no solo (Pulrolnik et al., 2009). O elevado incremento de AH na camada entre 35 e $45 \mathrm{~cm}$ poderia estar relacionado a um paleoclima mais seco a cerca de 2.500 anos $\mathrm{AP}$, conforme
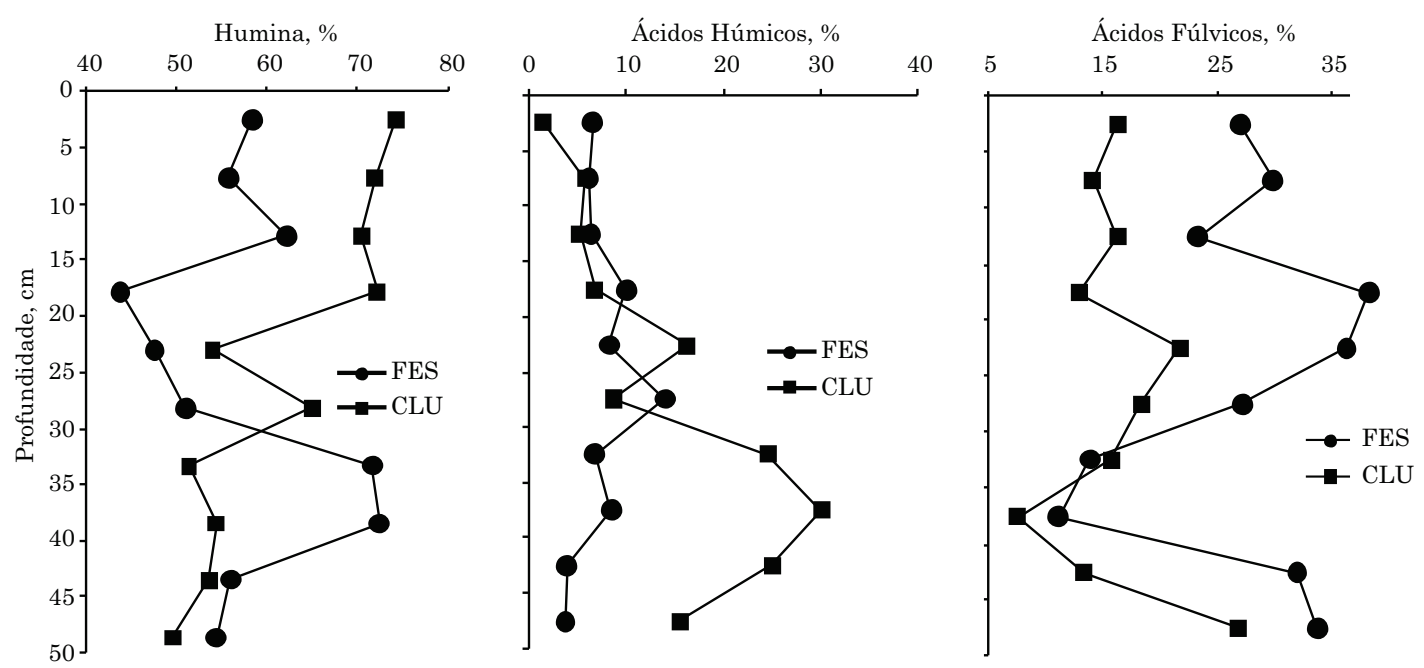

Figura 1. Teores médios de humina, ácidos húmicos e ácidos fúlvicos (\% MOS), em profundidade no Campo Limpo Úmido (CLU) e na Floresta Estacional Semidecidual (FES). 
sugerido por Horák et al. (2011) para turfeira localizada na serra do Espinhaço, MG, quando predominariam as plantas mais ricas em cutina e suberina.

\section{Movimentação de carbono no solo}

Os valores da relação $\mathrm{EA} / \mathrm{H}$, em que EA corresponde à soma das frações $\mathrm{AH}$ e $\mathrm{AF}$ e $\mathrm{H}$, a fração humina, não variaram entre as fitofisionomias avaliadas (Anova, $p=0,335212$ ) e foi de 0,83 no CLU e de 1,14 na FES, dentro da faixa de 0,36 a 9,94 , obtida por Valladares (2003) em Organossolos do Brasil. Segundo Benites et al. (2000), baixos valores dessa relação indicam elevados valores de movimentação de C. Além disso, esses valores indicam a estabilidade estrutural da matéria orgânica e constitui-se um índice melhor que os valores absolutos para avaliar a humificação da MOS. Os baixos valores encontrados na turfeira estudada indicaram que essa é um local de acúmulo de $\mathrm{C}$ atmosférico.

Não se observou variação nos valores da relação EA/ $\mathrm{H}$ em profundidade, apesar de grande incremento na camada de 20-25 cm no solo sob FES (Figura 2), pelo aumento do teor de AF. Os valores da relação EA/H menores do que 1 na maioria das amostras evidenciaram predomínio da fração insolúvel e mais recalcitrante da MOS (humina) ao longo dos perfis, em relação à fração alcalino-ácida solúvel (Canellas \& Santos, 2005; Silva et al., 2009b; Campos et al., 2010).

\section{Composição isotópica das substâncias húmicas}

Os valores médios de $\delta^{13} \mathrm{C}(\% \circ)$ das substâncias húmicas foram mais elevados sob CLU em relação à FES (Anova, $p=0,0000001$ ) e são semelhantes e seguem a mesma tendência dos valores de $\delta^{13} \mathrm{C}$ da MOS sob as duas fitofisionomias (Quadro 1). Em média, são mais enriquecidos em relação ao conjunto do tecido vegetal em 6,37\%o sob CLU e em 5,21\%o sob FES (Quadro 1). Esses valores estão acima do enriquecimento de $4 \%$ encontrado por Martinelli et. al. (2009) entre a vegetação e a MOS em solos minerais,
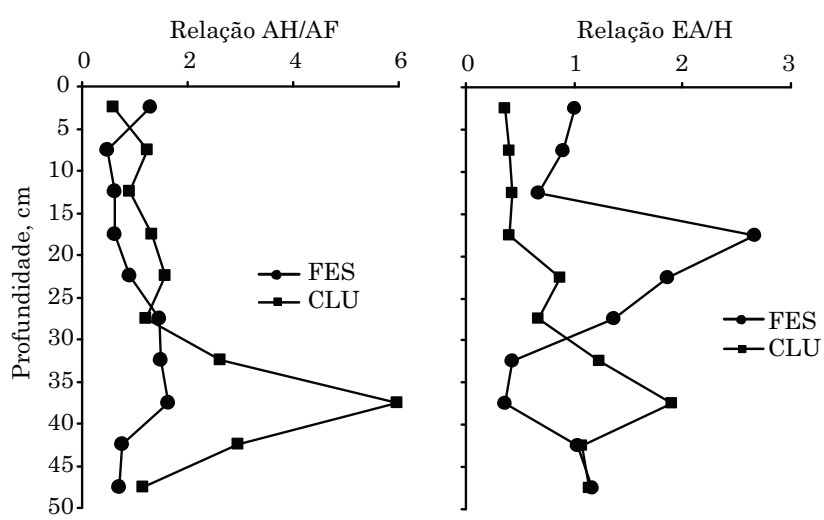

Figura 2. Relações AH/AF e EA/H em profundidade no Campo Limpo Úmido (CLU) e na Floresta Estacional Semidecidual (FES). sinalizando que em ambientes como as turfeiras, onde a decomposição da MOS é muito lenta, o enriquecimento em $\delta^{13} \mathrm{C}(\%)$ durante o processo de humificação é ainda mais elevado.

Os valores médios de $\delta^{13} \mathrm{C}$ da humina foram os que mais se aproximaram dos de $\delta^{13} \mathrm{C}$ da MOS sob FES, também verificado por vários autores (Canellas et al., 2003; Vidotto et al., 2007; Pulrolnik et al., 2009), observando-se empobrecimento de $0,28 \%$ em relação à MOS (Quadro 1). Tal constatação está de acordo com a sequência de humificação proposta por Stevenson (1994).

Os valores médios de $\delta^{13} \mathrm{C}$ das frações $\mathrm{AH}$ e $\mathrm{AF}$ foram superiores aos de $\delta^{13} \mathrm{C}$ da humina sob FES e inferiores sob CLU (Quadro 1). Essa diferença pode estar associada à decomposição mais rápida da espécie $\mathrm{C}_{4}$ do CLU em relação às espécies $\mathrm{C}_{3}$ lignificadas da FES ou à exsudação de ácidos orgânicos de baixo peso molecular (Ribas et al., 2008).

Os valores médios de $\delta^{13} \mathrm{C}$ dos $\mathrm{AH}$ e dos $\mathrm{AF}$ sob CLU e FES apresentaram desvios em relação à MOS, respectivamente, de $-0,25$ e $0,03 \%$ e de 1,10 e $0,53 \%$. Dessa forma, os AF são mais ricos em $\delta^{13} \mathrm{C}$ que a MOS

Quadro 1. Valores médios de $\boldsymbol{\delta}^{13} \mathrm{C}(\%)$ e $\boldsymbol{\delta}^{15} \mathbf{N}(\%)$ no conjunto do tecido vegetal, celulose da vegetação, lignina da vegetação, MOS, celulose no solo, lignina no solo, humina, ácido húmico e fúlvico no Campo Limpo Úmido (CLU) e na Floresta Estacional Semidecidual (FES) da turfeira da APA Pau-de-Fruta, Diamantina, MG

\begin{tabular}{|c|c|c|}
\hline Componente & $\delta^{13} \mathbf{C}$ & $\delta^{15} \mathbf{N}$ \\
\hline & \multicolumn{2}{|c|}{$-\% o-$} \\
\hline & \multicolumn{2}{|c|}{ CLU } \\
\hline Tecido vegetal & $-25,75$ & 1,31 \\
\hline Celulose da vegetação & $-24,80$ & 2,22 \\
\hline Lignina da vegetação & $-29,32$ & 1,07 \\
\hline MOS & $-19,35$ & 3,50 \\
\hline Celulose do solo & $-18,44$ & 2,92 \\
\hline Lignina do solo & $-20,11$ & 2,62 \\
\hline Humina & $-19,22$ & 3,60 \\
\hline Ácido húmico & $-19,60$ & 3,14 \\
\hline Ácido fúlvico & $-19,32$ & 2,97 \\
\hline \multirow{2}{*}{ Média } & $-21,77$ & 2,59 \\
\hline & \multicolumn{2}{|c|}{ FES } \\
\hline Tecido vegetal & $-29,90$ & $-3,17$ \\
\hline Celulose vegetação & $-28,39$ & $-2,07$ \\
\hline Lignina vegetação & $-32,21$ & $-2,20$ \\
\hline MOS & $-25,14$ & 4,06 \\
\hline Celulose no solo & $-25,07$ & 4,10 \\
\hline Lignina no solo & $-25,66$ & 2,45 \\
\hline Humina & $-25,42$ & 4,01 \\
\hline Ácido Húmico & $-24,04$ & 3,26 \\
\hline Ácido Fúlvico & $-24,61$ & 3,67 \\
\hline Média & $-26,72$ & 1,57 \\
\hline
\end{tabular}


e os $\mathrm{AH}$ são ligeiramente mais ricos em $\delta^{13} \mathrm{C}$, apenas sob FES. Como a FES apresenta elevado teor de AF, pode-se inferir que a decomposição lenta da lignina das espécies arbóreas produz $\mathrm{AF}$ a partir da humina ou dos resíduos vegetais frescos, como rota alternativa aos AH (Pulrolnik et al., 2009).

Encontraram-se variações entre valores de $\delta^{13} \mathrm{C}$ das substâncias húmicas das fitofisionomias em profundidade (Anova, $\mathrm{p}=0,042045$ ). Os valores de $\delta^{13} \mathrm{C}$ são superiores sob CLU em relação à FES em todas as profundidades (Figura 3), o que é indicativo de que grande parte das substâncias húmicas é formada a partir das espécies da fitofisionomia que coloniza o local amostrado; ou seja, a humificação ocorre sob influência do material autóctone.

Relações entre a lignina, celulose e as substâncias húmicas da MOS

Os valores isotópicos que ocorrem na vegetação $\left(\delta^{13} \mathrm{C}\right.$ no tecido vegetal, lignina e celulose) manifestamse com a mesma tendência no solo $\left(\delta^{13} \mathrm{C}\right.$ na MOS, lignina do solo e celulose do solo) nas duas fitofisionomias; ou seja, o tecido vegetal e a MOS estão empobrecidos em $\delta^{13} \mathrm{C}$ em relação à celulose e respectivamente enriquecido e empobrecido em relação à lignina (Quadro 1).

$\mathrm{O}$ teor de humina foi superior ao de lignina, $\mathrm{AH}$, $\mathrm{AF}$ e celulose, sob as duas fitofisionomias (Figura 4). A humina é o primeiro composto formado durante a humificação (Ribas et al., 2008) e acredita-se que essa representa grande parte dos compostos químicos presentes na MOS fresca, como lignina, celulose, hemicelulose, cutina, carboidratos solúveis, pectinas, gorduras, entre outros (Canellas \& Santos, 2005).

A lignina e a celulose são as principais macromoléculas orgânicas que dão origem às substâncias húmicas - SHs (Waksman \& Hutchings, 1936; Kononova, 1966). Entretanto, outros compostos químicos ocorrem associados às SHs (Camargo et al.,

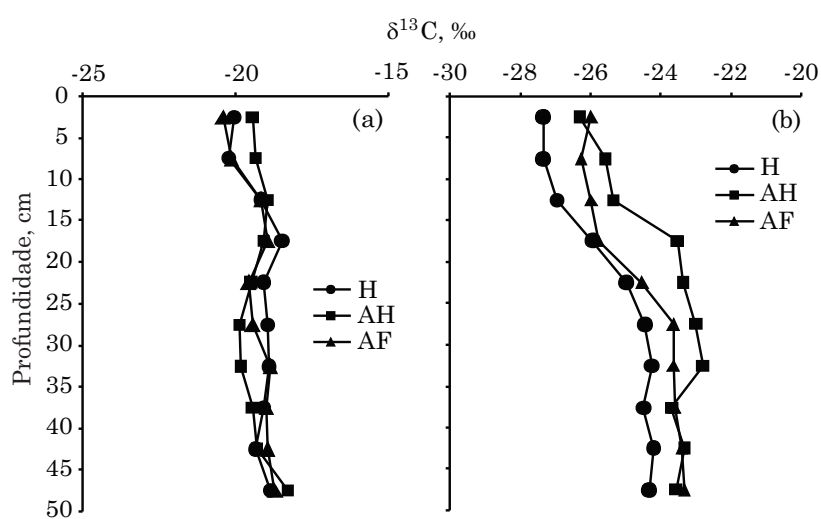

Figura 3. Valores médios de $\boldsymbol{\delta}^{13} \mathrm{C}(\%)$ da humina $(\mathrm{H})$, ácidos húmicos (AH) e ácidos fúlvicos (AF), em profundidade no Organossolo sob: (a) Campo Limpo Úmido (CLU); e (b) Floresta Estacional Semidecidual (FES).
1999; Andrade et al., 2005), mas com menor contribuição (Canellas \& Santos, 2005). A maioria dos desvios do teor de humina em relação aos teores de lignina+celulose no solo é positiva (Quadro 2), indicando que existem outros compostos associados à humina, notadamente no CLU, onde o teor de cutina $+\mathrm{N}$-lignificado das plantas e a sua recalcitrância são elevados (Brady \& Weil, 2002).

Os valores negativos desses desvios, mais evidentes sob a FES, apontam para baixas taxas de humificação, preservando a lignina e a celulose no solo. Restrições impostas por fatores paleoclimáticos (Pessenda et al., 1993) ou pelos baixos teores de nutrientes e baixa taxa de $\mathrm{O}_{2}$ dissolvido (Horák et al., 2010), que inibem a

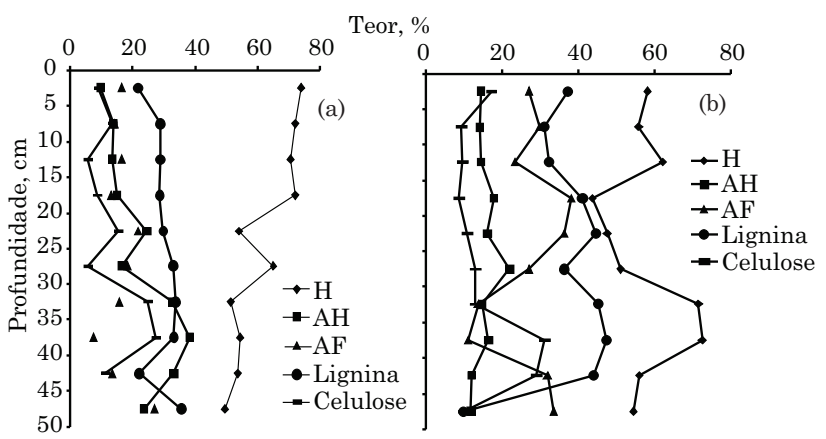

Figura 4. Teores médios de humina (H), ácidos húmicos (AH), ácidos fúlvicos (AF), lignina e celulose (\% MOS), em profundidade sob: (a) Campo Limpo Úmido (CLU); e (b) Floresta Estacional Semidecidual (FES).

Quadro 2. Desvios dos teores de humina $(\mathrm{H})$ em relação à lignina (\% MOS) e celulose (\% MOS) e dos teores de lignina (\% MOS) em relação à celulose (\% MOS), sob Campo Limpo Úmido (CLU) e sob Floresta Estacional Semidecidual (FES)

\begin{tabular}{ccccc}
\hline & \multicolumn{4}{c}{ Desvio } \\
\cline { 2 - 5 } Prof. & H-(lignina+celulose) & Lignina-celulose \\
\cline { 2 - 5 } & CLU & FES & CLU & FES \\
\cline { 2 - 5 } cm & \multicolumn{5}{c}{$\%$} & 5,6 & 20,1 \\
$0-5$ & 36,4 & 3,8 & 19,8 & 21,5 \\
$5-10$ & 34,2 & 15,2 & 15,5 & 22,7 \\
$10-15$ & 28,0 & 20,3 & 22,9 & 32,4 \\
$15-20$ & 38,1 & $-5,8$ & 21,2 & 33,8 \\
$20-25$ & 16,0 & $-8,2$ & 17,7 & 23,1 \\
$25-30$ & 17,2 & 1,7 & 28,0 & 32,1 \\
$30-35$ & 12,3 & 13,1 & 8,5 & 16,3 \\
$35-40$ & $-3,5$ & $-6,1$ & $-5,5$ & 14,9 \\
$40-45$ & 4,5 & $-16,9$ & 24,5 & 14,5 \\
$45-50$ & 2,8 & 20,2 & 15,8 & 23,1 \\
\hline & 18,6 & 3,7 &
\end{tabular}


atividade microbiológica (Campos et al., 2010), reduziriam bastante a primeira etapa da humificação, na qual os biopolímeros são quebrados pela ação de enzimas oxidativas secretadas pelos microrganismos (Stevenson, 1994; Canellas \& Santos, 2005).

Os teores de lignina na MOS foram superiores aos de celulose na MOS em praticamente todas as camadas (Figura 4), o que reforça a teoria da recalcitrância da lignina em relação à celulose durante a humificação (Stevenson, 1994; Andrade et al., 2005; Canellas \& Santos, 2005; Pulrolnik et al., 2009).

Os desvios dos teores médios de lignina em relação aos da celulose são maiores sob a FES do que sob o CLU (Quadro 2), o que corrobora a hipótese da recalcitrância da lignina das espécies arbóreas (Turner, 1986). Os teores mais elevados de lignina das espécies arbóreas promovem um efeito residual mais acentuado no solo (Camargo et al., 1999).

A síntese dos $\mathrm{AH}$ e $\mathrm{AF}$ poderia ocorrer a partir da degradação progressiva da celulose e do acúmulo residual de lignina. A degradação seria principalmente da celulose (Waksman \& Hutchings, 1936; Kononova, 1966; Stevenson, 1994; Canellas \& Santos, 2005; Pulrolnik et al.,2009), no processo de condensação abiótica que envolve a quebra da ligação de seus componentes moleculares e ressíntese de produtos macromoleculares (protótipos dos $\mathrm{AH}$ e AF). Essa ressíntese se daria por meio de reações entre as moléculas de lignina e os resíduos da celulose, que culminaria com a reação entre açúcares reduzidos com compostos aminados, evoluindo até macropolímeros de coloração escura e massa molecular elevada, sendo, propriamente, os AH e AF (Stevenson, 1994; Canellas $\&$ Santos, 2005).

\section{Precursores das frações húmicas do solo}

A similaridade da lignina em relação à humina, $\mathrm{AH}$ e $\mathrm{AF}$, utilizando o $\delta^{13} \mathrm{C}$ como parâmetro de análise, foi de, respectivamente, 91,$9 ; 88,0 ;$ e $87,3 \%$. Utilizando o mesmo parâmetro, a similaridade da celulose em relação à humina, $\mathrm{AH}$ e $\mathrm{AF}$ foi de, respectivamente, 87,$9 ; 85,3$; e $86,7 \%$, menor, em relação à lignina, para todas as SHs (Figura 5).
De acordo com Stevenson (1982), as SHs são formadas a partir da decomposição da lignina. Entretanto, na figura 5, está evidenciada também participação efetiva da celulose, como preconizado por Canellas \& Santos (2005).

A degradação de polímeros de plantas envolve reações de despolimerização e oxidação, que são catalizadas por enzimas. Polímeros de polissacarídeos, como a celulose, são degradados sob reações de despolimerização hidrolítica, enquanto a lignina é degradada, principalmente, por oxidação (Kononova, 1966). Na turfeira estudada, a atividade de $\mathrm{O}_{2}$ é muito baixa; o ambiente, redutor (Horák et al., 2010); e a taxa de oxidação, baixa.

A similaridade da lignina e celulose em relação às $\mathrm{SH}$ seguiu a mesma tendência: humina $>\mathrm{AH}>\mathrm{AF}$. A diminuição de similaridade segue a sequência da humificação (Stevenson, 1994; Canellas \& Santos, 2005) e estaria relacionada à diferenciação química dos compostos húmicos ao longo da humificação, tornando-os quimicamente complexos e heterogêneos (Tauk, 1990; Stevenson, 1994; Canellas \& Santos, 2005; Ribas et al., 2008).

\section{CONCLUSÕES}

1. Os teores de lignina e seus teores de $\delta^{13} \mathrm{C}$ são mais elevados na vegetação e na MOS sob FES em relação à vegetação e MOS sob CLU.

2. A humina, das frações das substâncias húmicas presentes na MOS, predomina nas duas fitofisionomias; os ácidos húmicos são mais altos sob CLU em relação à FES; e os ácidos fúlvicos são mais altos na FES em relação ao CLU.

3. $\mathrm{O} \delta^{13} \mathrm{C}$ da lignina apresenta alta similaridade com o das substâncias húmicas, da humina, dos ácidos húmicos e dos ácidos fúlvicos.

4. As variações na composição lignocelulósica das espécies que colonizam o CLU e a FES promovem
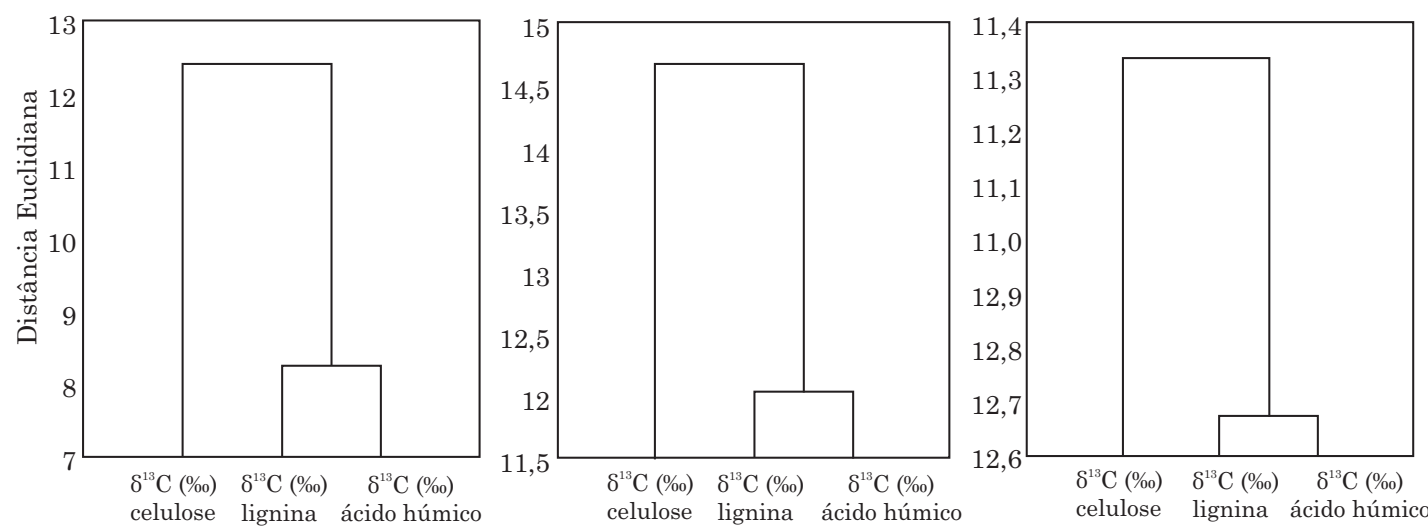

Figura 5. Dendrograma de conglomeração dos teores de ä13C (\%) da lignina e celulose da MOS, em relação a humina, ácidos húmicos e ácidos fúlvicos. 
diferenças nos processos de humificação da MOS, que são mais lentos sob FES e contribuem para uma formação mais rápida de Organossolos sob essa fitofísionomia, em relação ao CLU.

\section{AGRADECIMENTOS}

À FAPEMIG e ao CNPq, pela disponibilização de recursos; e à CAPES, pela concessão de bolsa de estudos.

\section{LITERATURA CITADA}

ANDRADE, C.A.; OLIVEIRA, C. \& CERRI, C.C. Qualidade da matéria orgânica e estoques de carbono e nitrogênio em Latossolo tratado com biossólido e cultivado com eucalipto. R. Bras. Ci. Solo, 29:803-816, 2005.

BAYER, C.; MARTIN-NETO, L. \& SAAB, S.C. Diminuição da humificação da matéria orgânica de um Cambissolo Húmico em plantio direto. R. Bras. Ci. Solo, 27:537-544, 2003.

BENITES, V.M.; KER, J.C. \& MENDONÇA, E.S. Fracionamento quantitativo de substâncias húmicas como auxiliar na identificação de diferentes solos da região sul do Brasil - VI RCC. VI RCC - Reunião de correlação, classificação e aplicação de levantamentos de solos RS/ SC/PR. In: URCIO, G., ed. Guia de excursão de estudos de solos nos Estados do Rio Grande do Sul, Santa Catarina e Paraná. Colombo, Embrapa, 2000.p.184-192. (Embrapa Florestas)

BOUTTON, T.W. Stable carbon isotope ratios of soil organic matter and their use as indicators of vegetation and climate change. In: BOUTTON, T.W. \& YAMASAKI, S., eds. Mass spectrometry of soils. New York, Marcel Dekker, 1996. p.47-82.

BOUTTON, T.W. Stable carbon isotopes ratios of natural materials. II. Atmospheric, terrestrial, marine and freshwater environmental. In: COLEMAN, D.C. \& FRY, B., eds. Carbon isotopes techniques. New York, Academic Press, 1991. p.155-171.

BRADY, N. \& WEIL, R.R. The nature and properties of soils. 13.ed. Prentice Hall, Upper Saddle River, 2002. 960p.

BREEMEN, N.V. \& BUURMAN, P. Soil formation. Dordrecht, Kluwer, 1998. 376p.

CAMARGO, F.A.O.; SANTOS, G.A. \& GUERRA, J.G.M. Macromoléculas e substâncias húmicas. In: SANTOS, G.A. \& CAMARGO, F.A.O., eds. Fundamentos da material orgânica do solo: Ecossistemas tropicais e subtropicais. Porto Alegre, Gênesis, 1999. p.27-40.

CAMPOS, J.R.R. Caracterização, mapeamento, volume de água e estoque de carbono da turfeira da Área de Proteção Ambiental Pau-de-Fruta, Diamantina - MG. Diamantina, Universidade Federal dos Vales do Jequitinhonha e Mucuri, 2009. 101p. (Dissertação de Mestrado)
CAMPOS, J.R.R.; SILVA, A.C.; VASCONCELLOS, L.L.; SILVA, D.V.; ROMÃO, R.V.; SILVA, E.B. \& GRAZZIOTTI, P.H. Pedochronology and development of peat bog in the environmental protection area Pau-de-Fruta Diamantina, Brazil. R. Bras. Ci. Solo, 34:1965-1975, 2010.

CANELLAS, L.P. \& SANTOS, G.A. Humosfera: Tratado preliminar sobre a química das substâncias húmicas. Campos dos Goytacazes, Universidade Estadual do Norte Fluminense, 2005. 287p.

CANELLAS, L.P.; VELLOSO, A.C.X.; MARCIANO, C.R.; RAMALHO, J.F.G.P.; RUMJANEK, V.M.; REZENDE, C.E. \& SANTOS, G.A. Propriedades químicas de um Cambissolo cultivado com cana-de-açúcar, com preservação do palhiço e adição de vinhaça por longo tempo. R. Bras. Ci. Solo, 27:935-944, 2003.

CERRI, C.C. \& VOLKOFF, B. Matéria orgânica de três solos dos campos inundáveis da ilha de Marajó. R. Bras. Ci. Solo, 12:93-100, 1988.

DABIN, B. Les matíeres organiques dans les sols tropicaux normalement drainés. Cah. ORSTOM, Ser. Pedol., 28:197$215,1981$.

DICK, D.P.; GONÇALVES, C.N.; DALMOLIN, R.S.D.; KNICKER, H.; KLAMT, E.; KÖGEL-KNABNER, I.; SIMOES, M.L. \& MARTIN-NETO, L. Characteristics of soil organic matter of different brazilian Ferralsols under native vegetation as a function of soil depth. Geoderma, 124:319-333, 2005.

DUCHAUFOUR, Ph. Pédogenèse et classification. In: DUCHAUFOUR, Ph. \& SOUCHIER, B., eds. Pedologie. Paris, 1977. v.1. 478p.

EMPRESA BRASILEIRA DE PESQUISA AGROPECUÁRIA EMBRAPA. Proposta para classificação de Organossolos em níveis inferiores com base nas frações húmicas. Campinas, Embrapa Monitoramento por Satélite, 2003. 35p. (Boletim de Pesquisa e Desenvolvimento, 2)

FARQUHAR, G.D.; O'LEARY, M.H. \& BERRY, J.A. On the relationship between carbon isotope discrimination and the intercellular carbon dioxide concentration in leaves. Aust. J. Plant Physiol., 9:121-37, 1982.

FERNANDES, F.A.; CERRI, C.C. \& FERNANDES, A.H.B.M. Alterações na matéria orgânica de um podzol hidromórfico pelo uso com pastagens cultivadas no pantanal MatoGrossense. Pesq. Agropec. Bras., 34:1943-1951, 1999.

FREITAS, H.A.; PESSENDA, L.C.R.; ARAVENA, R.; GOUVEIA, S.E.M.; RIBEIRO, A.S.; BOULET, R. Late Quaternary vegetation dynamics in the Southern Amazon Basin inferred from carbon isotopes in soil organic matter. Quaternary Res., 55: 39-46, 2001.

FONTANA, A.; BENITES, V.M.; PEREIRA, M.G. \& ANJOS, L.H.C. Substâncias húmicas como suporte à classificação de solos brasileiros. R. Bras. Ci. Solo, 32:2073-2080, 2008.

GARAY, I.; KINDEL, A. \& JESUS, R.M. Diversity of humus forms in the atlantics forestry ecosystems (Brazil): The tableland Atlantic forest. Acta Oecologica, 16:553-570, 1995. 
GOUVEIA, S.E.M.; PESSENDA, L.C.R.; ARAVENA, R.; BOULET, R.; SCHEEL-YBERT, R.; BENDASSOLI, J.A.; RIBEIRO, A.S. \& FREITAS, H.A. Carbon isotopes in charcoal and soils in studies of paleovegetation and climate changes during the late Pleistocene and the Holocene in the southeast and centerwest regions of Brazil. Global Planet Change, 33:95-106, 2002.

GRONING, M. \& GROOT, P.A. ed. Handbook of stable isotope analytical techniques. Amsterdam, Elsevier, 2004. p.874-906.

HAIR, J.F.; ANDERSON, R.E.; TATHAM, R.L. \& BLACK, W.C. Análise multivariada dos dados. 5.ed. Porto Alegre, Artmed, 2005. 593p.

HARTSHORN, G.S. Neotropical forest dynamics. Biotropica, 12:23-30, 1980.

HÖGBERG, P. Tansley review No. $97{ }^{15} \mathrm{~N}$ natural abundance in soil-plant systems. New Phytol., 137:179-203, 1997.

HORÁK, I.; VIDAL TORRADO, P.; SILVA, A.C. \& PESSENDA, L.C.R. Pedological and isotopic relations of a highland tropical peatland, Mountain Range of the Southern Espinhaço (Brazil). R. Bras. Ci. Solo, 35:41-52, 2011.

HORÁK, I.; VIDAL-TORRADO, P.; SILVA, A.C. \& LUZ, C.F.P. 9000 years of vegetation and climate change in SE Brazil: preliminary pollen record of a tropical peatland (Pau-deFruta, Diamantina, MG). In: ANTHROPOCENE: LINKING POLLEN AND GEOCHEMISTRY RESEARCH, 1, Santiago de Compostela, ES. Anais ... Santiago de Compostela, ES, Galician Universitary System, 2010. CD-ROM

HORÁK, I.; SILVA, A.C.; VIDAL-TORRADO, P.; FERREIRA, C.A.; RACEDO, J.R. \& CORTIZAS, A.M. Turfeiras da Serra do Espinhaço Meridional - MG: II - Caracterização e fracionamento químico da matéria orgânica. In: CONGRESSO BRASILEIRO DE CIÊNCIA DO SOLO, 26., Gramado, 2007. Anais... Gramado, SBCS, 2007. CDROM.

KONONOVA, M.M. Transformations of organic matter and their relation to soil fertility. Sov. Soil Sci., 8:1047-1057, 1966.

LICHTFOUSE, E.; BERTHIER, G.; HOUOT, S.; BARRIUSO, E.; BERGHEAUD, V. \& VALLA, T. Stable carbon isotope evidence for the microbial origin of $\mathrm{C}^{14}-\mathrm{C}^{18} \mathrm{n}$-alkanoic acids in soils. Org. Geochem., 23:849-852, 1995.

LOSS, A.; PEREIRA, M.G. \& BRITO, R.J. Distribuição das substâncias húmicas em solos de tabuleiros sob diferentes coberturas vegetais. R. Univ. Rural, Série Ci. Vida, 26: 57-69, 2006.

MARTINELLI, L.A.; OMETTO, J.P.H.B.; FERRAZ, E.S.; VICTORIA, R.L.; CAMARGO, P.B. \& MOREIRA, M.Z. Desvendando questões ambientais com isótopos estáveis. São Paulo, Oficina de Textos, 2009. 130p.

MARTINELLI, L.A.; PESSENDA, L.C.R.; ESPINOZA, E.; CAMARGO, P.B.; TELlES, E.C.; CERRI, C.C.; VICTORIA, R.L.; ARAVENA, R.; RICHEY, J. \& TRUMBORE, S. Carbon-13 variation with depth in soils of Brazil and climate change during the Quaternary. Oecologia, 106:376-381, 1996.
MUNHOZ, C.B.R. \& FELFILI, J.M. Fitossociologia do estrato herbáceo-subarbustivo em Campo Limpo Úmido no Brasil Central. Acta Bot. Bras., 28,905-913, 2008.

NIEROP, K.G.J. Origin of aliphatic compounds in forest soil. Org. Geochem., 29:1009-1016, 1998.

O'LEARY, M.H. Carbon isotopes in photosynthesis. BioScience, 38:325-36, 1988.

OADES, J.M. The retention of soil organic matter in soils. Biogeochemistry, 5:35-70, 1988.

PESSENDA, L.C.R.; CAMARGO, P.B.; CRUZ, M.V.L.; LISI, C.S. \& VALENCIA, E.P.E. O Laboratório de Radiocarbono do CENA/USP no Programa Internacional de Intercooperação Laboratorial de Resultados. Quím. Nova, 16:221-223, 1993

PIMENTEL-GOMES, F. Curso de estatística experimental. 12.ed. São Paulo, Nobel, 1987. 466p.

PULROLNIK, K.; BARROS, N.F.; SILVA, I.R.; NOVAIS, R.F. \& BRANDANI, C.B. Estoques de carbono e $\mathrm{N}$ em frações lábeis e estáveis da matéria orgânica de solos sob eucalipto, pastagem e cerrado no Vale do Jequitinhonha - MG. R. Bras. Ci. Solo, 33:1125-1136, 2009.

RIBAS, L.M.; BALDOTTO, M.A.; CANELLAS, L.P. \& REZENDE, C.E. Qualidade e mobilidade da matéria orgânica de sistemas adjacentes à Lagoa de Cima, Campos dos Goytacazes - RJ. Geochim. Bras., 22:103-112, 2008.

SANAIOTTI, T.M.; MARTINELLI, L.A.; VICTORIA, R.L; TRUMBORE, S.E. \& CAMARGO, P.B. Past vegetation changes in Amazon Savannas determined using carbon isotopes of soil organic matter, Biotropica, 34:2-16, 2002.

SILVA, A.C.; SILVA, E.V.; SILVA, B.P.C.; CAMARGO, P.B.; PEREIRA, R.C.; BARRAL, U.M.; BOTELHO, A.M.M. \& VIDAL TORRADO, P. Composição lignocelulósica e isótopica da vegetação e da matéria orgânica do solo de uma turfeira tropical. I - composição florística, fitomassa e acúmulo de carbono. R. Bras. Ci. Solo, 37:121-133, 2013.

SILVA, A.C.; PEDREIRA, L.C.V.S.F. \& ALMEIDA ABREU, P.A. Serra do Espinhaço Meridional: Paisagens e ambientes. Belo Horizonte, O Lutador, 2005. 271p.

SILVA, A.C.; HORAK, I.; MARTINEZ-CORTIZAS, A.; VIDALTORRADO, P.; RACEDO, J.R.; GRAZZIOTTI, P.H.; SILVA, E.B. \& FERREIRA, C.A. Turfeiras da Serra do Espinhaço Meridional: I Caracterização e classificação. R. Bras. Ci. Solo, 33:1385-1398, 2009a.

SILVA, A.C.; HORAK, I.; VIDAL-TORRADO, P.; MARTINEZCORTIZAS, A.; RACEDO, J.R. \& CAMPOS, J.R.R. Turfeiras da Serra do Espinhaço Meridional: II. Influência da drenagem na composição elementar e na composição das substâncias húmicas. R. Bras. Ci. Solo, 33:1399-1408, 2009b.

SILVA, V.E. Relações entre a composição lignocelulósica e isotópica da vegetação e da matéria orgânica de uma turfeira tropical. Diamantina, MG, Universidade Federal dos Vales do Jequitinhonha e Mucuri, 2011. 164p. (Dissertação de Mestrado) 
SPARKS, D. Environmental soil chemistry. San Diego, Academic Press, 1995. 267p.

STEVENSON, F.J. Humus chemistry: Genesis, composition and reactions. New York, John Wiley, 1982. 450p.

STEVENSON, F.J. Humus chemistry: Genesis, composition, reactions. 2.ed. New York, John Wiley \& Sons, 1994. $496 \mathrm{p}$.

TAN, K.H. Humic matter in soil and the environment. New York, Marcel Decker, 2003. 385p.

TAUK, S.M. Biodegradação de resíduos orgânicos no solo. R. Bras. Geoci., 20:299-301, 1990.

TURNER, N.C. Adaptation to water deficits: A changing perspective. Aust. J. Plant Physiol., 13:175-190, 1986.
VALLADARES, G.S. Caracterização de Organossolos, auxílio à sua classificação. Seropédica, Universidade Federal Rural do Rio de Janeiro, 2003. 142p. (Tese de Doutorado)

VICTORIA, R.L.; FERNANDES, F.; MARTINELLI, L.A.; PICCOLO, M.C.; CAMARGO, P.B. \& TRUMBORE, S. Past vegetation changes in the brazilian Pantanal arboreal-grass Savanna ecotone by using carbon isotopes in the soil organic matter. Global Change Biol., 1:101-108, 1995.

VIDOTTO, E.; PESSENDA, L.C.R.; RIBEIRO, A.S.; FREITAS, H.A. \& BENDASSOLLI, J.A. Dinâmica do ecótono florestacampo no sul do estado do Amazonas no Holoceno, através de estudos isotópicos e fitossociológicos. Acta Amaz., 37:385-400, 2007.

WAKSMAN, S.A. \& HUTCHINGS, I.J. Decomposition of lignin by microorganisms. Soil Sci., 42:119-130, 1936. 